bottom. Where the depth is not very great only the thinnest and most delicate shells are removed, and the others accumulate, forming vast deposits; with increasing depth other shells disappear, only the thicker ones reaching the bottom; but in the very greatest depth nearly every trace of these surface shells is removed, or we find them making up but $I$ or 2 per cent. of the deposit. It is possible that this process of solution of the shells may be somewhat accelerated in the deepest layers of water by the great pressure.

In the deepest parts of the abysmal areas, where the carbonate of lime shells are either wholly or partially removed from the bottom, there are met with those peculiar deep-sea clays, the origin of which has been the subject of considerable discussion. They are principally made up of clayey matter resulting from the disintegration of volcanic rocks, and derived chiefly from floating pumice and showers of volcanic ashes. Mixed up with these clayey and volcanic materials are thousands of sharks' teeth, some of them of gigantic size, and evidently belonging to extinct species, also very many ear-bones, and a few of the other bones of whales, some of them also probably belonging to extinct species. These organic fragments are generally much decomposed and surrounded and infiltrated by depositions of peroxide of manganese, which is a secondary product arising from the decomposition of the volcanic material in the deposits. Again, we have in some places numerous zeolitic minerals and crystals formed in the clay, also as secondary products. Lastly, there are numerous minute spherules of native iron and other rare substances, covered with a black coating of oxide, which are referred with great certainty to a cosmic origin-probably the dust derived from meteoric stones as they pass through the higher regions of our atmosphere. Quartz, which is so abundant as a clastic element in deposits around the continents, is almost absent from the deposits of the abysmal regions.

In the abysmal regions, then, which cover one half of the earth's surface, which are undulating plains from two to five miles beneath the surface of the sea, we have a very uniform set of conditions: the temperature is near the freezing point of fresh water, and the range of temperature does not exceed $7^{\circ}$, and is constant all the year round in any one locality ; sunlight and plant-life are absent, and although animals belonging to all the great types are present, there is no great variety of form nor abundance of individuals; change of any kind is exceedingly slow. In the more elevated portions of the regions the deposits consist principally of the dead shells and skeletons of surface animals, in the more depressed ones they consist of a red clay mixed with volcanic fragmental matter, the remains of pelagic vertebrates, cosmic dust, and manganese iron nodules and zeolitic crystals, the latter being secondary products arising from the decomposition of the minerals which have long remained exposed to the hydrochemical action of sea-water. The rate of accumulation is so slow in some of these clays that we find the remains of tertiary species lying on the bottom alongside the remains of those inhabiting the present seas. It has not yet been possible to recognise the analogues of any of the deposits now forming in the abysmal regions in the rocks making up the continents.

It is quite otherwise in the areas bordering the continentsthe uncoloured areas on the maps. Almost all the natter brought down to the ocean in suspension is deposited in this region, which is that of variety and change with respect to light, temperature, motion, and biological relations. It extends from the sea-shore down, it may be, to a depth of three or four miles, and outwards horizontally from 60 to 300 miles, and includes all partially inclosed seas, such as the North Sea, Mediterranean, Caribbean, and many others. The upper or continental margin of the area is clearly defined by the coast line, which is continually changing from breaker action, elevation, and subsidence; the lower or abysmal margin of the region is less clearly marked out, passing insensibly into the abysmal. regions and terminating where the mineral particles from the neighbouring continents disappear from the deposits. In the surface waters the temperature varies from over $80^{\circ}$ in the equatorial to $28^{\circ}$ in the Polar regions, and from the surface to the ice-cold water at the lower margins of the regions there is in the tropics an equally great range of temperature. Plants and animals flourish luxuriantly near the shore, and animals extend in relatively great abundance down to the lower limits of the region. Here we find now in process of formation deposits which will form rocks similar to those making up the great bulk of continental land, such as schists, shales, sandstones, marls, greensands, and chalks; the glauconitic grains of the green muds and phosphatic nodules can be traced in all stages of formation, and probably, though much less certainly, the initial stages in the formation of flint.

Throughout all geological time the deposits formed in this border or transitional area appear to have been pushed, forced, and folded up into dry land, through the secular cooling of the earth and the necessity of the outer crust to accommodate itself to the shrinking solid nucleus within. These depositions do not in themselves cause elevation or subsidence, but most probably the changes of pressure, resulting from them, tend to destroy the existing equilibrium and to produce lines of weakness along the borders of the continents and in the regions of enclosed and partially enclosed seas, with the result that the borders of continental land have been more frequently thrown into folds and have suffered greater lateral thrusts than any other regions on the surface of the earth.

On the other hand, while we know that there are vast deposits of carbonate of lime taking place over some portions of the abysmal regions, and that volcanic outbursts occur in others, still these are not comparable with the great changes which have taken place in the past, and are now taking place, on the continents and along their borders.

When the coral atolls and barrier reefs which are scattered over the tropical regions of the great oceans are examined in the light of recent discoveries, it is found that their peculiar form and structure can be accounted for by the truncation of some submarine cones through breaker action; by the upward growth of others through the accumulation of marine deposits; by the solution of dead coral through the action of sea-water; and lastly by a study of the source and direction from which the food supply reaches the reef-building animals. That this in all probability is the true history of the origin of these marvellous structures is further confirmed by the recent examination of the upraised coral atolls of the Pacific by Dr. Guppy, and the researches of Mr. Buchanan into the characters of oceanic banks and shoals. Coral atolls and barrier reefs, instead of pointing out great and general subsidences, must be regarded rather as indicating areas of great permanence and stability.

The results of many lines of investigation, then, seem to show that in the abysmal regions we have the most permanent areas of the earth's surface, and he is a bold man who still argues that in Tertiary times there was a large area of continental land in the Pacific, that there was once a Lemuria in the Indian Ocean, or a continental Atlantis in the Atlantic.

In this rapid review of recent oceanographical researches my chief object has been to show you the wide range of the observations, for every science has been enriched by a large store of new facts. It matters little whether the opinions which I have given as to the bearing of some of these be correct or not; for the observations are now or will soon be in the hands of scientific men, and errors in interpretation or deduction will soon be exposed. The great point is that there has been a vast addition to human knowledge, and it must be a matter of satisfaction that our own country has taken so large a share in these important investigations as to call forth the admiration of the scientific men of all countries. You have learnt from the President's address that there is usually not much to say in commendation of the Government for its liberality to science. But in the matter of deep-sea investigation, neglecting mere details, we can say that the successive Governments of the Queen during the past twenty years have, either from design or by accident, undertaken a work in the highest interests of the race, have carried it on in no mean or narrow patriotic spirit, and are likely to carry it to a termination in a manner worthy of a great, free, and prosperous people.

\section{ON A SUPPOSED PERIODICITY OF THE CYCLONES OF THE INDIAN OCEAN SOUTH OF THE EQUATOR ${ }^{1}$}

IN papers printed in the Reports for $1872,1873,1874$, and 1876 , I endeavoured to show that there were grounds for supposing that the cyclones of the Indian Ocean south of the equator increased in number, extent, and intensity from a minimum in one year to a maximum in another, and then decreased to a minimum, the period or cycle apparently corresponding with the eleven-year period of solar activity.

From the data given in the last of these papers (Report for 
1876, p. 267), it would appear that from 1856 to 1875 the years of minimum cyclone activity were 1856 and 1867 , and the years of maximum activity $186 \mathrm{I}$ and 1872 , but that the results for each of tho:e years did not differ much from the results for the ycar immediately preceding or following it, the variation near the turming-points being small.

Before giving a brief outline of the results which have been obtained since 1875 , it may be well to mention that the sources of information were the same as in former years. Two clerks were constantly occupied in tabulating the meteorological observations contained in the log-books of vessels that arrived in the harbour of Port Louis from different places. The number of days' observations tabulated in each year-that is, observations extending over twenty-four hours and made in different parts of the ocean--was as follows:-

\begin{tabular}{lll|lll} 
Years & \multicolumn{2}{c|}{ Days' Obscrvations } & Ycars & \multicolumn{2}{c}{ Thays' Observations } \\
1876 & $\ldots$ & 17,017 & 1881 & $\ldots$ & 16,473 \\
1877 & $\ldots$ & 17,005 & 1882 & $\ldots$ & 15,089 \\
1878 & $\ldots$ & 17,050 & 1883 & $\ldots$ & 16,930 \\
1879 & $\ldots$ & 15,889 & 1884 & $\ldots$ & 16,700 \\
1880 & $\ldots$ & 17,306 & & &
\end{tabular}

The tables give an average of 46 observations of 24 hours each for every day of the nine years over the frequented parts of the ocean.

All details and reports respecting hurricanes, storms, or gales were recordcd in separate registers.

For each day on which there was a gale in any part of the ocean between the equator and the parallel of $34^{\circ} \mathrm{S}$. a chart was prepared, "showing as ncarly as possible the positions of the vessels the direction and force of the wind, \&c., at a certain hour, namely, noon on the mericlian of $60^{\circ} \mathrm{E}$.

From these synoptic charts the details given from hour to hour in the log-books, and all the information obtained from other sources, the position of the centres of cyclones at noon on each day were determined, and the tracks laid down on separate charts.

Nine cyclone-track charts have thus been prepared, namely, one for each of the years $1876-84$.

These track-charts, together with the twonty that had previously been prepared for the years $1856-75$, show, as far as has yet been ascertained, the tracks of the cyclones of the Indian Ocean south of the equator in each of the years $1856-84$, and the tracks for the ycars $1848-55$ are nearly ready.

With respect to the period $1876-84$, the areas of cyclones and the distances traversed have not yet been determined, but upo $n$ the whole the number and duration of the cyclones decreased to a minimum in I880, and then increased till, in I884, they were more than double of what they were in $\mathbf{1} 880$.

From the accompanying track-charts for the eleven years 1856 ,

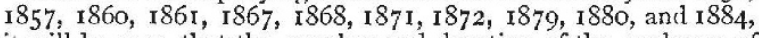
it will be seen that the number and duration of the cyclones of 1856 and 1857 were much less than those of the cyclones of 1860 and $186 \mathrm{I}$; that the number and duration of the cyclones of 1867 and 1868 were much less than those of 1860 and $186 \mathrm{r}$ on the one hand, and also than those of 1871 and 1872 on the other; and that the number and duration of the cyclones of 1879 and 1880 were much less than those of the cyclones of 1871,1872 , and $188_{4}$.

It would appear, however, that in 1884 there was less cyclone activity than in 1861 and 1872 .

\section{UNIVERSTTY AND EDUCATIONAL INTELLIGENCE}

OXFORD. - The commencement of Michaelmas Term does not witness many changes in the personnel of scientific departments in Oxford. $\Lambda$ lecturer in Human Anatomy has been appointed, and commences work this term. The opening of the new physiological laboratories at the back of the University Museum completes the scheme for physiological education which has been so strenuously opposed by the enemies of scientific research in the University.

One of the most noticeable changes in Oxford to outward view is the opening of the new buildings in Trinity College. The new block of buildings, designed by Mr. Jackson, stretches backward from Kettle Hall in Broad Street to the Bathurst building and college chapel, making a new quadrangle bounded on the south by Broad Street and 'Trinity Cottages (now thrown into the "quad"), on the west by Balliol, on the north by the chapel and Bathurst, and to the east by the new buildings. The new "quad" is only second in size to "Tom quad" in Christchurch.

With our respect and sorrow for Dr. Bulley, late President of Magdalcn, who died during the vacation, is mingled a feeling of intense satisfaction and not a little surprise at the appointment of his successor.

In Mr. T. II. Warren, the new President, Magdalen has gained a man no less distingui hed for his scholarship than for his liberal views on education. Under the virile direction of her new president, Magdalen, already prominent among our Colleges for her recognition of natural science, may well hope to extend her usefulness. In the liberal Oxford of to-day-in'the leaching as opposed to the voting University-Mr. Warren's clection has been received with enthusiasm.

The following courses of lectures and classes in Natural Science will be given during the cnsuing term :- In the Physical Department of the Museum Prof, B. Price lectures on HydroMechanics. Prof. Clifton lectures on Ohm's Law ; Mr. Selby lectures on Electrostatics; and Mr. Walker on Elementary Mechanics. The laboratory is open for practical instruction daily.

At the University observatory Prof. Pritchard gives three courses. Firstly, on the Application of the Theory of Proba. bilities to Astronomical Observation; secondly, on Spherical Astronomy; thirdly, on the Astronomy referred to by Polybius and other classical writers.

At Christchurch Mr. Baynes lectures on Conduction of Heat, and has a class for practical Instruction in Electrical Measurements.

At Balliol Mr. Dixon lectures on Elementary Magnetism and Electricity.

In the Chemical Department Prof. Odling lectures on the Phenic Compounds; Dr. Watts gives a course on General Organic, and Mr. Fisher gives a course on General Inorganic Chemistry.

The laboratories are open daily for practical instruction.

At Christchurch Mr. Vernon Harcourt has a class for Quantitative Analysis.

In the Biological Departments Prof. Moseley lectures on the Comparative Anatorny of the Vertebrata; Mr. Spencer lecture: on Elcmentary Animal Morphology.

Prof. Burdon-Sanderson lectures on the Physiology of Motion, Mr. Dixey lectures on Histology, and Mr. Thomson on Human Anatomy.

The Morphological and Physiological Laboratories are open daily for practical instruction.

Mr. Jackson lectures on Parthenogenesis, Mr. Thompson on Osteology, and Mr. Poulton on the Distribution of Animals.

Prof. Westwood lectures on the Orders of Winged Arthropoda. Prof. Prestwich lectures on Geology : Physical Questions, Volcanic Action, \&c.

At the Botanic Garden Prof. Gilbert lectures on the Results of Ficld Experiments, and Prof. Balfour gives practical instruction in Vegetable Morphology and Physiology.

Dr. Tylor lcctures at the Museum on Social and Religious Systems.

\section{SCIENTIFIC SERIALS}

THE only structural paper in the August and September numbers of the Fournal of Botany is by Mr. Thomas Hick, on the caulotaxis of British Fumariacex. "Thronghout the whole of this ordcr," he states, "as represented in the British Isles, a remarkable unity of organisation prevails. In all cases, save that of Corydalis solida, the main stem is a sympodium or pseudaxis, composed of binodal caulomeres, except in the basal region, where they are of a higher order, and often in the apical region also, where they become uninodal." The paper is illustrated by woodcuts. In addition the student of descriptive botany will find two papers by Mr. J. G. Baker : a monograph of the genus Gethyllis (with two plates), and a synopsis of the Cape species of $K$ niphofia, in addition to a continuation of his synopsis of the genus Selaginella; and the numbers are not wanting in other papers of interest in descriptive, systematic, and geographical botany.

THE number for October is an unusually interesting one. Mr. H. N. Ridley gives descriptions and figures of two recent additions to the British flora, both belonging to the Cypcracerc, and both from Scotland: Schamels ferruginens, L., and Carex 